\title{
Illiquidity and Pricing Biases in the Real Estate Market
}

\author{
Zhenguo Lin \\ Fannie Mae \\ 3900 Wisconsin Avenue \\ Washington DC 20016 \\ Kerry D. Vandell \\ School of Business \\ University of Wisconsin - Madison \\ 975 University Avenue \\ Madison, WI 53706
}

\begin{abstract}
This paper addresses the micro-analytic foundations of illiquidity and price dynamics in the real estate market by integrating modern portfolio theory with models describing the real estate transaction process. Based on the notion that real estate is a heterogeneous good that is traded in decentralized markets and that transactions in these markets are often characterized by costly searches, we argue that the most important aspects defining real estate illiquidity in both residential and commercial markets are the time required for sale and the uncertainty of the marketing period. These aspects provide two sources of bias in the commonly adopted methods of real estate valuation, which are based solely on the prices of sold properties and implicitly assume immediate execution. We demonstrate that estimated returns must be biased upward and risks downward. These biases can be significant, especially when the marketing period is highly uncertain relative to the holding period. We find also that real estate risk is closely related to investors' time horizons, specifically that real estate risk decreases when the holding period increases. These results are consistent with the conventional wisdom that real estate is more favorable to long-term investors than to short-term investors. They also provide a theoretical foundation for the recent econometric literature (e.g., Gatzlaff and Haurin (1997, 1998), Fisher, Gatzlaff, Geltner, and Haurin (2003), and Goetzmann and Peng (2003)) which finds evidence of "smoothing" of real estate returns. Our findings help explain the apparent "risk-premium puzzle" in real estate -- i.e., that ex-post returns appear too high, given their apparent low volatility - and can lead to the formal derivation of adjustments that can define real estate's proper role in the mixed-asset portfolio.
\end{abstract}

Presented before the Gutmann Center Symposium on Real Assets and Portfolio Management, University of Vienna, March 27, 2006. Not for quotation without permission of the authors. The authors wish to thank Philippe Jioron, Nai-Fu Chen, and participants in a workshop at the University of California-Irvine, anonymous referees at Real Estate Economics and editor David Ling, and Shaun Bond at Cambridge University for their comments on an earlier draft. All errors remain our own. 


\section{Illiquidity and Pricing Biases in the Real Estate Market}

\section{Introduction: The Risk Premium Puzzle in Real Estate}

Proper pricing, evaluation of investment performance, and allocation of real estate in a mixed-asset portfolio has proven to be a vexing question. Real estate is highly heterogeneous, is thinly traded over relatively-long holding periods, and is traded through a transactions process that is typically not a simultaneous-bid auction but instead is a sequential bid process without recall which may involve significant transaction costs. Thus, it displays characteristics of illiquidity, but a type of illiquidity that may depart from that displayed by thinly-traded securities.

A substantial literature has evolved over time, summarized in Section II, that attempts to correct for various of these idiosyncratic characteristics of real estate as an asset class. The present paper contributes to that literature by exploring in a formal framework the micro-analytic foundations that underlie the divergent trading mechanism in real estate integrating the traditional literature in modern portfolio theory with more recent models describing the real estate transactions process. Section III will first describe formally how real estate return and risk were traditionally measured and estimated. Then we will briefly examine sources of bias in estimation that have been discussed in the literature. Finally, we will turn to the primary contributions of this paper: consideration of two sources of bias in the measurement of risk and return originating from two distinct types of risk (which we term marketing period risk and liquidation risk) attributable to lack of recognition of the fact that (1) it is the ex ante risk and return expectations that are the relevant considerations for investor behavior, not ex post realizations of transaction prices at the point of sale, and (2) observed transaction prices with positive marketing periods do not reflect the underlying distribution of property valuations. These biases, reflecting the heterogeneity of real estate assets, a transaction process characterized by sequential bidding without recall, and an extended and uncertain marketing period, could under plausible conditions account for much of what has been considered to be the anomalous pricing characteristics of real estate.

\section{The Evolution of Valuation Approaches to the Measurement and Estimation of Real Estate Return and Risk}

Early empirical studies in the real estate literature comparing real estate returns to those of other asset classes consistently concluded that real estate as an asset class not only had extremely low volatility, but also extremely high risk-adjusted returns, relative to what would be expected from contemporary asset valuation theory. ${ }^{1}$ More recent

\footnotetext{
1 During the period 1978 to 1998 , for example, the standard deviation of the National Council of Real Estate Investment Fiduciaries (NCREIF) total return series was 3.66\%, which is less than one-fifth that for common stocks $(20.82 \%$ for large cap stocks and $40.04 \%$ for small cap stocks), and less than half that for long-term bonds $(8.32 \%$ for corporate bonds and $8 \%$ for government bonds). In terms of riskadjusted return, NCREIF's Sharpe ratio (1.47) was more than six times that for bonds (between 0.17 and 0.28 ) and at least three times that for both large cap stocks (0.41) and small cap stocks (0.35) (Ibbotson
} 
studies have argued that these estimated returns to real estate are less volatile than those of common stocks because real estate returns, such as the NCREIF index, are estimated by using both appraisal data and transaction prices, and appraisals tend to "smooth" real estate values and make them less volatile (e.g. Geltner (1991), Clayton, Geltner and Hamilton (2001), Geltner, MacGregor and Schwann (2003)). After excluding appraisal data in the NCREIF property sample, however, Geltner and Goetzman (2000) constructed a transaction-based NCREIF index and found that the standard deviation of the transaction-based NCREIF return index increased only slightly, from $3.66 \%$ to $4.26 \%$ in the period 1978 to 1998 , but was still very low compared to that for stocks and bonds. In addition, the annual return of the transaction-based NCREIF index was $9.2 \%$, and its Sharpe ratio (1.27) remained extremely high. ${ }^{2}$

Such results persistently presented the question: was there a risk premium puzzle in real estate? In other words, did contemporary real estate valuation methods misprice real estate's risk-adjusted return? Traditional empirical estimates of risk and return for real estate and financial assets were based on observed historical prices. For example, in a given time period, suppose the price of an asset at time $t$ is $P_{t}(t=0,1,2, \ldots, T)$. Then the simplest and most commonly used formulae for estimating the return and risk of this asset were

$$
\begin{gathered}
\hat{r}=\frac{\sum_{i=1}^{T} \frac{P_{i}-P_{i-1}}{P_{i-1}}}{T} \\
\hat{\sigma}=\sqrt{\frac{\sum_{i=1}^{T}\left(\frac{P_{i}-P_{i-1}}{P_{i-1}}-\hat{r}\right)^{2}}{T-1}}
\end{gathered}
$$

Associates, 2005). This pattern was even more pronounced for earlier periods when common stocks performed less well. For example, Firstenberg, Ross and Zisler (1988) found that the standard deviation of stock returns was over five times greater than that of real estate returns, and the standard deviation of bond returns was three times that of real estate returns, while the average returns of real estate were slightly higher than that of both stocks and bonds. Hoag (1980) developed a property index based on a sample of 463 unleveraged properties and found its return to be $14.2 \%$, compared to common stock returns of $3.7 \%$ reported by Ibbotson and Sinquefield (1982) for the corresponding time period. Zerbst and Cambon (1984) found the return of Commingled Real Estate Funds (CREF) to be $14.0 \%$, compared to $6.5 \%$ for common stocks over the same period. By examining the standard deviation of returns, they also found that real estate returns appeared far less volatile than those for common stocks and corporate bonds. For example, the standard deviation of CREF returns for $1973-1981$ was $4.7 \%$, compared to $21.2 \%$ for common stocks and $7.8 \%$ for corporate bonds in the same period. Other studies that found similar results for the comparable time period include Ibbotson and Fall (1979), who found, in the period 1947 to 1978, the standard deviation of real estate $(3.5 \%)$ was about one-fifth that of stocks $(18 \%)$ and real estate's Sharpe ratio $(1.31)$ was about three times that of stocks (0.38). During the period 1960 - 1973, Kelleher (1976) found real estate's Sharpe ratio to be even higher, at about eight times that of stocks (1.75 vs. 0.21).

${ }^{2}$ Some also argued that real estate has such a high risk-adjusted return because it often involves high transaction costs. This argument has been challenged by Kallberg, Liu and Greig (1996). 
where current prices included any current dividends as well as capital appreciation.

Due to the heterogeneity and infrequency of trading of real estate assets, it became apparent that we could not directly apply the formulae above to the prices of each sold property over time to estimate real estate return and volatility. The simplest approach adopted to correct this problem was to compose a real estate price index as the average of the values of the properties being studied. This was the approach used in the composition of the commonly-referenced NCREIF index of property performance in the commercial market and the National Association of Realtors (NAR) Index in the residential market.

A more sophisticated approach was represented by econometrically-estimated indices of property values over time. The commonly-used approaches here include the repeat-sales model (first proposed by Bailey, Muth, and Nourse (1963) and popularized by Case and Shiller (1987) and currently the source of the OFHEO Residential Price Index), the hedonic model (the source of the HUD Residential Price Index), the hybrid model (see Quigley (1995), and the appraisal-based model (see Quan and Quigley (1991)). We refer to Lin (2004) for a detailed discussion of the strengths and weaknesses of each of these methodologies. Suffice it to say that each is subject under certain conditions to presenting certain biases in the estimation of "true" returns.

These biases originate from four sources, which have been recognized in the literature: (1) appraisal bias, which can originate from a bias in the holding-period return, even if the appraised value is an unbiased estimator (Giliberto, 1988), or from a bias caused by the "smoothing" that is inherent in using appraisal-based returns (Geltner (1989b, 1991), Ross and Zisler (1991)); (2) sample selection bias, which is created by the fact that transaction prices used for estimation by necessity could represent a biased sample of the entire stock (e.g., Gatzlaff and Haurin $(1997,1998)$ for the residential market and Munneke and Slade (2000) for the commercial market), often addressed by using Heckman's two-step procedure and the inclusion of the inverse Mills ratio; (3) transformation bias, created in the repeat-sales model under certain conditions, when repeat-sales estimators are essentially equal-weighted cross-sectional averages, while the returns of equal-weighted portfolios are arithmetic averages of cross-sectional individual asset returns (Considered in Shiller (1991), Geltner and Goetzmann (2000), and Goetzman and Peng (2002)); and (4) aggregation bias, caused either by spatial aggregation bias (see Thomas and Stekler (1983) and Goodman (1998)) or temporal aggregation bias (see Geltner (1993) and Dombrow, Knight, and Sirmans (1997)), representing uneven clustering of transactions across space or time.

A final pair of recent papers (Fisher, Gatzlaff, Geltner, and Haurin (2003), Goetzmann and Peng (2003)) identify an additional source of bias, namely the bias associated with differences in the ease of selling a property over time, which they relate to differences in the marketing period or time-on-market (TOM). In this scenario, when the market is "hot", there are many bidders in the market competing to purchase properties, which tends to result in a shorter TOM at which the reservation price of the buyer meets or exceeds the reservation price of the buyer. Commensurate with this phenomenon is an increase in the volume of sales because the distribution of buyer 
reservation prices is shifted up relative to the distribution of seller reservation prices. In their view, these variations over time are directly related to each other and represent proxies for variations in the degree of liquidity present in the real estate market at any period of time. Thus, observed prices (controlling for all the sources of bias identified above) are biased estimates of value unless the degree of "liquidity", as they define it (constant TOM or constant sales volume) is controlled for. The resulting "constant liquidity" price index then represents an unbiased "true" measure of price performance over time. ${ }^{3}$

The above two papers, in particular, are important precursors to ours. They recognize the endogenous relationship between marketing period, trading volume, and observed selling price and the fact that this has to do with variations in the degree of liquidity, as operationally defined in some way, in the sense of how easy or quick one is able to sell a property at the "optimal" sales price under the circumstances in the market, and how that "optimal" (observed) price may be observed under different liquidity conditions. The current paper differs from them in the following ways:

Both papers are primarily intended to be econometric papers that derive proper econometric corrections for biases created by different trading volumes or TOM's over time (essentially extending the Heckman sample-selection bias corrections earlier to control also for varying TOM's and/or trading volumes). They do not include formal theoretical derivations of what constitutes the fundamental essence of the risk characterizing the transaction process in real estate that produces the observed bias.

Both papers operationally define liquidity at a "constant" (average or typical) level using the proxy of a constant (average) TOM or trading volume. They implicitly assume in their operational definition that such conditions (i.e. constant TOM or trading volume) are both necessary and sufficient to define constant liquidity. They do not recognize either the possibility that trading volumes and TOM could vary under a broader definition of constant liquidity (for example, consider that trading volumes vary considerably over time in the purely "liquid" stock market). Nor do they recognize that under a broader definition of liquidity, a constant TOM may not be consistent with a constant trading volume (for example, these are correlated, but by no means directly related in the real estate market). Finally, they do not recognize that even if they both (or even one) were constant, liquidity, by a broader definition could vary. ${ }^{4}$

\footnotetext{
3 The Goetzmann and Peng model differs from the Fisher et al. model primarily in that it presents a simpler econometric approach to identifying the bias and incorporates direct, rather than implied measures of trading volume.

4 For example, conceivably, stability in both time on market and transaction volume could occur as the result of the right confluence of changes in sellers' and buyers' reservation price distributions over time in
} 

bias to be one that brings the price index to represent an "average" or "typical" degree of liquidity in the market (by their definition). This means an average or typical TOM or trading volume. Rather, the proper correction to compare the performance of real estate as an asset class in a mixed asset portfolio against the performance of other asset classes and to estimate proper allocation of real estate in the portfolio, is to adjust real estate price movements to represent full liquidity. While their operational definition of liquidity as TOM is meaningful when the notion of complete liquidity is considered (TOM $=0$ ), this does not seem to be the case if their operational definition is trading volume, since such volume would approach infinity (or constant trading of all properties at every point in time).

The present paper does not deal specifically with the econometric correction of observed sales prices. Rather we delve theoretically into the fundamental processes driving price risk and marketing-period risk over time. This formal analytical framework allows us to define a continuum of liquidity conditions for the individual asset, from fully liquid, when it is optimal for the seller to accept the first offered bid at time period zero, to a low degree of liquidity, when the marketing period experienced before the acceptance of a bid becomes optimal may be quite long (or in the limit even infinite, in which case the sale is not observed). Aggregating these individual situations up, given property, buyer, and seller heterogeneity, then provides a broader set of observed conditions in the market over time with respect to price, TOM, and trading volume that reflect a more complex distribution of degrees of liquidity. Allowing these relationships to vary in a broader framework as the optimal TOM is moved toward zero (full liquidity), then traces out the corrected price dynamics for real estate as a liquid asset, on an apples-to-apples basis with other liquid assets in the portfolio. The next section develops this framework.

\section{The Real Estate Transaction Process}

Intuition. We begin with the formalization of the real estate transaction process as distinct from that in financial markets. Intuitively, due to the uncertainty of the marketing period in the real estate market, the formation of transaction prices in the real estate market is very different from that in the financial market.

First, the classical (perfectly competitive, frictionless, and complete) financial market is a homogeneous and thickly traded market. At any instant, there is unrestricted availability of buyers and sellers at the market price, and prices are determined by market clearing. On the other hand, the real estate market is a heterogeneous and thinly traded

the face of macro-market dynamics. 
market, and its prices are formed by sellers' sequential search and their optimal stopping rule: accepting the first price above their reservation price (e.g. Arnold (1999) and Yavas (1992)).

Second, prices exist in the financial market at any time. Sellers can sell their financial assets at the market price at any time without waiting. In contrast, real estate prices exist only when there is a current buyer with an offer price that is at least as high as the seller's reservation price. When there is either no buyer or an offer price is below the seller's reservation price, the real estate price does not exist and the sellers have to continue to search for the next buyer. Hence, sellers cannot sell their real estate assets at any given price without waiting. Due to the nature of stochastic arrival of potential buyers and the uncertainty of their offer prices, time on market cannot be fully controlled by the sellers. Therefore, unlike the financial market, real estate investors face not only price risk, as in the financial market, but also marketing period risk.

The Model. ${ }^{5}$ Exhibit 1 illustrates these price dynamics in the context of the transaction process in the real estate market. Suppose an investor purchases a real estate asset at time 0 and places it on the market at time $T_{H}$, and suppose $\tilde{t}$ is a possible (discrete) marketing period with a sale price $\widetilde{P}_{T_{H}+\tilde{t}}$, where $\left(\tilde{t}=t_{1}, t_{2}, \ldots\right) t_{1}$ is the waiting time of the first buyer, $t_{2}$ is the waiting time of the second buyer, and $t_{i}$ is the waiting time of $i$ th buyer. ${ }^{6}$ In each passing period, the seller faces random arrivals of potential buyers. There are two possibilities: (1) a successful sale when a potential buyer is present and his/or her asking price equals or exceeds seller's minimum accepted price; or (2) no successful sale when there is no buyer present or an asking price is too low for the seller to accept.

Assume the seller's reservation price at the time of the $i$ th buyer's arrival is $P_{t_{i}}^{\text {reservation }}$ and the buyer's bidding price is $P_{t_{i}}^{\text {bid }}$. Note that the reservation price is optimally, not arbitrarily, set by the seller. By the optimal stopping rule, the probability of a successful sale at time $t_{i}$ given that the real estate has not been sold is

$$
p_{i}=\operatorname{Pr} o b\left(P_{t_{i}}^{\text {bid }} \geq P_{t_{i}}^{\text {reservation }}\right)
$$

Therefore, we can deduce that the real estate asset will be sold at the first offer with probability $p_{1}$, at the second offer with probability $p_{2}\left(1-p_{1}\right)$, at the third offer with probability $p_{3}\left(1-p_{1}-p_{2}\left(1-p_{1}\right)\right)$, and so on. Since $p_{i}(i=1,2, \ldots)$ is largely

\footnotetext{
${ }^{5}$ The analysis that follows is consistent with that developed by others (e.g., see Fisher, Gatzlaff, Geltner, and Haurin (2003)) who recognize the stochastic nature of the transaction process for real estate as it affects transaction prices and time on market. We develop it explicitly only to set the stage for later development of our revised risk/return measures.

${ }^{6}$ For mathematical simplicity, we consider a discrete-time model. However, the analysis can be readily extended to a continuous-time model with no substantive change in our findings.
} 
determined by the market, the probability of a successful sale at each offer cannot be fully controlled by the seller. ${ }^{7}$

Since the seller does not know when a potential buyer will arrive after $T_{H}$ when the asset is put on the market, the arrival time $T_{H}+t_{i}$ is also stochastic. We thus denote it as $T_{H}+\widetilde{t}_{i}$ to emphasize its randomness. Exhibit 1 illustrates the possibility of sale at time $T_{H}+\widetilde{t}_{i}\left(\widetilde{t}_{i}=t_{1}, t_{2}, \ldots t_{i}, \ldots\right)$, where $T_{H}$ is the seller's holding time and $\widetilde{t}_{i}$ is the seller's marketing period. Hence, the marketing time $\tilde{t}_{i}$ of a successful sale not only depends on the arrival distribution of potential buyers but also on whether buyers' bidding prices are higher than the seller's reservation price. Since both the arrival distribution and seller's reservation price are closely related to market conditions, the uncertainty of the marketing period is beyond the seller's control.

If the asset is successfully sold at marketing period $t(t=0,1,2, \ldots)$, the seller receives ex-post return $\widetilde{R}_{T_{H}+t}$. The probability of sale in marketing period $t$ is denoted by $p_{t}(t=0,1,2,3, \ldots)$, which characterizes real estate illiquidity and satisfies, $\sum_{t=0}^{\infty} p_{t}=1$.

A transaction price $P^{T}$ can be observed if and only if a bid price $P$ equals or exceeds the reservation price $P^{*}$ :

$$
P^{T}= \begin{cases}P & \text { if } P \geq P^{*}, \\ \text { unobserved } & \text { if } P<P^{*} .\end{cases}
$$

Where:

$$
P=V_{0}+\varepsilon, \quad \varepsilon \sim N\left(0, \sigma_{\varepsilon}^{2}\right)
$$

and $V_{o}$ represents the distribution of market valuations.

Equations (3) and (4) can be combined as

$$
P^{T}=V_{0}+\left[\varepsilon \mid \varepsilon \geq P^{*}-V_{0}\right]
$$

Similar properties with different sellers may transact very differently. For a variety of reasons, some sellers may have to lower their reservation prices in order to sell their houses more quickly than others. Equation (5) implies that the distribution of transaction prices varies over reservation price levels. Therefore, strictly speaking the return and risk in the real estate market are "seller-specific".

\footnotetext{
${ }^{7}$ It is possible, indeed likely, that sellers can influence the rate of arrival of potential buyers, and possibly the likelihood and level of buyers' bids by strategic setting of their asking price. We shall ignore this possibility for the present and assume realistically the seller lacks at least some degree of control.
} 
As in Goetzmann and Peng (2003), Munneke and Slade (2000), Englund, Quigley and Redfearn (1999), and Gatzlaff and Haruin (1998), we assume a potential buyer, on the other hand, offers a bid price based on some figure representing the "market valuation". Hence, the bid price is a price from a single distribution of market valuation, which is not "seller-specific".

As we know, the only prices that can be observed in the real estate market are transaction prices, and bid prices below the seller's reservation price are unobservable directly through observed transaction prices. Thus, the market valuation distribution cannot be directly observed in the real estate market. We will revisit this issue when we discuss the valuation bias present from the use of observed real estate transactions as an estimate of the underlying valuation distribution.

The Distribution of Buyers' Arrivals. Let us now solve the above problem for specific distributions for buyers' arrivals and bid prices. The typical assumption of buyers' stochastic arrival is the Poisson process, with a constant arrival rate in each point of time. Following Gatzlaff and Haurin (1998), Salant (1991), Haurin (1988), and Lippman and McCall (1986), we assume that a potential seller receives bid prices from potential buyers at a rate of one per period (units of time can be made arbitrarily small). ${ }^{8}$

The Distribution of Bid Prices. Regarding the distribution of bid prices, Arnold (1999) and Sirmans, Turnbull and Dombrow (1995) assume that the bid distribution is over $[\underline{p}, \bar{p}]$ with density function $f\left(P^{\text {bid }}\right)$, where $\underline{p}(\bar{p})$ is the minimum (maximum) bid price. ${ }^{9}$ The assumption of a time-invariant distribution of expected offer prices is probably too simple for two reasons. First, the underlying value of a specific property is typically expected to increase over time, especially for residential property in nominal terms. According to OFHEO's repeat-transactions home price index (estimated using data from Fannie Mae and Freddie Mac), home prices rose in excess of the rate of inflation over the last 20 years in all but a few markets and in nominal terms in all markets. Hence, at least for the residential market, we typically would expect the distribution of underlying home values to shift upward over time. Second, after a relatively long holding period, buyers tend to have weaker information regarding the true market value of a specific property, and thus are more likely to agree on a price that may differ substantially from the market value. ${ }^{10}$ Therefore, the underlying risk should increase as time passes between transactions (Case and Shiller 1987). Consistent with

${ }^{8}$ The assumption is made for technical simplicity. Anglin (2003), Arnold (1999), Glower, Haruin and Hendershott (1998) and Miceli (1989) assume that an arrival rate of $\lambda$ per period. A more complicated model would allow buyers to respond to sellers' asking price, i.e., a higher asking price implies a lower arrival rate, but that is beyond the scope of this analysis.

${ }_{9} \bar{p}$ can be regarded as the seller's asking price. We recognize that in unique circumstances in which the market is particularly "hot", bidding by potential purchasers raise $\bar{p}$ above the asking price. Inclusion of this possibility would not change the essential results of our analysis.

10 This is because of the increasing remoteness of the "anchoring" provided by the previous transaction price. 
these two facts, we assume that the distribution of bid prices varies over time. In particular, we assume that it is distributed over $\left[\tau \underline{p}+P_{0}, \tau \bar{p}+P_{0}\right]$ at time $\tau$, where $P_{0}$ is the original purchase price at time $0 .{ }^{11}$

Yavas (1992) and Read (1988) assume the bid density function $f(p)$ is uniformly distributed. For technical simplicity, we adopt the same assumption here. ${ }^{12}$ Hence, the buyers' bid price $P_{\tau}^{\text {bid }}$ at time $\tau$ is distributed as,

$$
f\left(P_{\tau}^{b i d}\right)=\left\{\begin{array}{lc}
\frac{1}{\overline{(p}-\underline{p}) \tau}, & P^{b i d} \in\left[\tau \underline{p}+P_{0}, \tau \bar{p}+P_{0}\right] \\
0, & \text { otherwise }
\end{array}\right.
$$

The seller decides whether or not to accept an offer based on the reservation price for the property. ${ }^{13}$ At each point in time, the optimal marketing strategy for the seller is to accept the first bid above the reservation price, and to reject all bids below. Like the buyers' bid price, we allow a time-varying reservation price and denote this as $p_{\tau}^{*}$. Therefore, in any period, there exist two possibilities: First, a transaction occurs when a buyer arrives with a bid price $P_{\tau}^{b i d} \geq p_{\tau}^{*}$ and the seller accepts that offer and sells the property for that price. Second, no transaction occurs if an offer price $P_{\tau}^{\text {bid }}<p_{\tau}^{*}$. If there is no transaction, no deal is reached and the seller will continue to search for the next buyer. Thus, observable real estate transaction prices (denoted by $P_{\tau}^{T}$ ) must be in the range of $\left[p_{\tau}^{*}, \bar{p} \tau+P_{0}\right]$, and in order to trade at an observable transaction price, the real estate seller experiences the uncertainty of sale in each period. ${ }^{14}$

Holding other things equal, the higher the underlying market value of a property, the higher the seller's reservation price. Accordingly, we assume that the seller's

\footnotetext{
11 Note that it is still possible for the bid distribution to represent a possibility of declining prices using this distribution if $\underline{p}$ is negative. Of course negative bid prices are not possible; our assumption is consistent, however, with those stochastic interest rate models that permit negative interest rates to allow fitting of observed interest rate drifts. In a more generalized model, we could also add a constant (or constants) to the $\tau$ term which could best fit anticipated drifts in property values over time. The essential results of our model would be preserved regardless.

12 In fact, our essential results would hold under a wide variety of more complex distribution function assumptions.

${ }^{13}$ To evaluate possible distributions of reservation prices is not the focus of this analysis. We treat the distribution as given. Lippman and McCall $(1986,1976)$ and DeGroot (1970) have some discussion on this.

${ }^{14}$ In the real estate market, most sellers sell their assets by exercising the optimal stopping rule: to accept all bids above the reservation price and to reject all bids below. Henceforth we assume observable transaction prices are all prices that are at least as high as sellers' reservation prices.
} 
reservation price also increases with time. For analytical tractability and without loss of generality, we further assume that, for a particular seller, at time $\tau$ his reservation price $p_{\tau}^{*}$ is $p^{*} \tau+P_{0} .^{15}$

Probability of Sale: Constant Hazard Rate. Given the discussion above, in any period there are two possibilities: a transaction or no transaction. If a buyer's offer is too low for the seller to accept, the seller has to wait and continue to search for the next buyer. In this model, the probability of having a transaction in each period given the property is not sold can be obtained as $\frac{\bar{p}-p^{*}}{\overline{\bar{p}-\underline{p}}}$, which for the time being we shall assume is constant over time. Hence, the probability of sale at marketing period $t(t=0,1,2,3 \ldots)$ (denoted by $\widetilde{T}_{M}$ ) is a geometric distribution,

$$
\operatorname{Prob}\left(\widetilde{T}_{M}=t\right)=\pi(1-\pi)^{t}
$$

Where,

$$
\pi=\frac{\bar{p}-p^{*}}{\bar{p}-\underline{p}}
$$

and $\pi$ is the (constant) hazard rate of sale.

Equations (7) and (8) highlight two interesting facts. First, the probability of a successful sale in each period not only depends on the seller's reservation price $\left(p^{*}\right)$, but also depends on the dispersion of buyers' valuation, $(\bar{p}-\underline{p})$, and a lower reservation price indicates a higher probability of sale. Therefore, the reservation price plays an important role in the determination of matching probability between sellers and buyers. Second, sellers cannot sell their asset at a predetermined time with certainty. Since $p^{*}=\underline{p}$ rarely occurs in the real estate market, $\operatorname{Prob}\left(\widetilde{T}_{M}=t\right)<1$ holds for all $t$. In other words, the time required for sale in the real estate market is a random variable (e.g. Trippi 1977).

Expected Marketing Period: Constant Hazard Rate. Having derived the probability of a successful sale in each period, we next study how long the seller is expected to wait on the market. By definition, the expected marketing period can be expressed as follows,

$$
E\left[\widetilde{T}_{M}\right]=\sum_{t=0}^{\infty} t \pi(1-\pi)^{i}
$$

\footnotetext{
15 There could of course be circumstances, once a property is placed on the market and a seller has received insufficient interest given her motivation to sell, she my revise her reservation price downward based upon a revised perspective of the underlying bid distribution. This complexity could certainly be introduced in a more elaborate model, but it is beyond the scope of the present effort.
} 
Simplifying (9) yields,

$$
E\left[\widetilde{T}_{M}\right]=\frac{1}{\pi}-1
$$

Equation (10) indicates that the probability of sale is uniquely related to the expected marketing period through the (constant) hazard rate $\pi$.

Taking Equations (10) and (8) together, we can conclude that real estate sellers sell their assets immediately only when they decide to accept whatever price the buyer can offer $\left(p^{*}=\underline{p}\right.$, hence $\pi=1$ and $\left.E\left[\widetilde{T}_{M}\right]=0\right)$.

\section{Real Estate Illiquidity and Marketing Period Bias}

Given the above development of the formal structure of the real estate transactions process, we can now proceed to formally defining real estate illiquidity and marketing period bias. We adopt as an operational measure of real estate illiquidity the first and second moment of the random variable representing the marketing period $\widetilde{T}_{M}=\widetilde{t}_{i}$, or the expected time required for sale $t_{M}$ and the uncertainty in the marketing period $\sigma_{t m}^{2}$

$$
\begin{aligned}
t_{M} & =E\left[\widetilde{T}_{M}\right]=\sum_{t=0}^{\infty} t p_{t} \\
\sigma_{t_{M}}^{2} & =\operatorname{Var}\left[\widetilde{T}_{M}\right]=\sum_{t=0}^{\infty}[t-E[t]]^{2} p_{t}
\end{aligned}
$$

In Appendix 1, to better understand how the distribution of probability of a possible sale over the marketing period affects the expected marketing period and its volatility, we consider three special cases - that in which the distribution of the probability of sale over time is constant, uniform, and exponential. Consistent results are obtained in each case: A higher level of illiquidity implies a longer expected marketing period and a greater uncertainty in marketing period, typically an increase of the same order magnitude for both measures.

Ex Post vs. Ex Ante Measures of Return: As discussed previously, associated with each random marketing period variable and its first and second moments, as defined above, is also a random return variable with its first and second moments - the expected

\footnotetext{
${ }^{16}$ Note that we are now permitting the probability of sale over time $p_{t}$ to vary. Since $\operatorname{Var}(\tilde{t})=\sum_{t=0}^{\infty}[t-E[t]]^{2} p_{t}=\operatorname{Var}\left(\tilde{t}+T_{H}\right)$, and $\tilde{t}+T_{H}$ is the time of sale, we use the terms uncertainty of marketing period and uncertainty of time of sale interchangeably. Our operational definition of illiquidity we feel gets at the essence of illiquidity in the real estate market, having to do with the anticipated marketing time for an individual asset and the uncertainty in that measure. Higher order treatment of the stochastic marketing time variable is certainly possible but beyond the scope of the current analysis.
} 
return and risk. A seller placing his real estate asset on the market after holding it for $T_{H}$

periods receives return $\widetilde{R}_{T_{H}+\tilde{t}}$ upon successfully selling it at time $T_{H}+\widetilde{t}\left(\tilde{t}=t_{1}, t_{2}, \ldots\right)$.

We define the ex-ante measure of return as the forward-looking measure unconditional upon a successful sale at a specific point in time. The ex-ante expected return and risk can be defined as follows,

$$
\begin{gathered}
E^{\text {ex-ante }}\left[\widetilde{R}_{T_{H}+\tilde{t}}\right]=\underset{\widetilde{t}}{E}\left[\underset{\widetilde{R}}{E}\left[\widetilde{R}_{T_{H}+\tilde{t}} \mid \widetilde{t}\right]\right] \\
\left.\operatorname{Var}^{\text {ex- ante }}\left[\widetilde{R}_{T_{H}+\tilde{t}}\right]=\underset{\widetilde{t}}{E}\left[\underset{\widetilde{R}}{E}\left[\widetilde{R}_{T_{H}+\tilde{t}}-E^{\text {ex-ante }}\left[\widetilde{R}_{T_{H}+\tilde{t}}\right]\right]^{2} \mid \widetilde{t}\right]\right]
\end{gathered}
$$

Note that ex-ante expected return and risk are closely related to the uncertainty of the marketing period $(\tilde{t})$.

Concurrently, we define the ex-post measure of return as the observed return based upon the observed sales price at the time at which the property is sold. Those estimation methodologies for return discussed above that accept the sales price as an unbiased estimate of the market value at the time of sale are all ex-post return measures. They ignore possible underlying variations in the marketing period, hence variations in the degree of liquidity present. If returns generated in this manner are compared to returns generated for fully liquid assets such as stocks, then implicitly this measure is assuming real estate possesses full liquidity (i.e., is a measure conditional upon immediate execution $(\tilde{t}=0)$ ). In this situation, ex-post expected return and risk are defined as follows,

$$
\begin{gathered}
E^{\text {ex- post }}\left[\widetilde{R}_{\widetilde{t}+T_{H}} \mid \widetilde{t}=0\right]=E\left[\widetilde{R}_{T_{H}}\right] \\
\operatorname{Var}^{\text {ex- post }}\left[\widetilde{R}_{\widetilde{t}+T_{H}} \mid \widetilde{t}=0\right]=E\left[\widetilde{R}_{T_{H}}-E\left[\widetilde{R}_{T_{H}}\right]\right]^{2}
\end{gathered}
$$

Since the ex-post expected return and risk are independent of the uncertainty of the marketing time, the ex-post measure of return only involves price risk.

What is the practical importance of these ex ante vs. ex post measures of return and risk? As we know, historical prices are the data recorded on an "ex-post", or after the fact basis of successful sales. In reality, a real estate seller who tries to sell his asset does not know when it will actually be sold; i.e., actually possesses an "ex-ante" view of the risk he faces. In order to distinguish our alternative approach from traditional valuation approaches to real estate asset performance, we label our new measure the ex-ante measure and the traditional measure the ex-post measure. Marketing period bias in this framework is therefore naturally defined as the pricing difference between these two measures. Thus, marketing period bias essentially captures the effect of the uncertainty of marketing period on real estate pricing. 
Equations (13)-(16) indicate that ex-ante expected return and risk are identical to ex-post expected return and risk if and only if assets can be sold immediately. We can prove that in the presence of uncertainty in the marketing period, however, and under realistic assumptions for the distribution of returns, the ex ante expected return remains equivalent to the ex post return, but the ex ante variance is higher than the ex post variance. This is demonstrated in the following theorem:

Theorem 1: Suppose an investor purchases a real estate asset at time 0 and markets it in period $T_{H}$. Assume the probability of being sold at marketing period $\tilde{t}(\tilde{t}=0,1,2, \ldots, \infty)$ is $p_{\tilde{t}}\left(\sum_{\tilde{t}=0}^{\infty} p_{\tilde{t}}=1\right)$, with ex-post (total) return $\widetilde{R}_{T_{H}+\tilde{t}}$, which is distributed with mean $\left(T_{H}+\tilde{t}\right) u$ and variance $\left(T_{H}+\tilde{t}\right) \sigma^{2}$, where $u=$ the periodic mean ex-post return and $\sigma^{2}$ $=$ the periodic mean ex-post variance. Then

(1) The periodic ex-ante expected return is the same as the periodic expected ex-post return:

$$
u^{\text {ex-ante }}=u \text {; }
$$

and

(2) The periodic ex-ante variance is higher than the periodic ex-post variance, specifically,

$$
\left(\sigma^{e x-\text { ante }}\right)^{2}=\sigma^{2}+\frac{\operatorname{Var}(t)}{T_{H}+E[t]} u^{2}
$$

[Proof provided in Appendix 2]

The assumption that the ex-post return $\widetilde{R}_{T_{H}+t}$ is distributed with mean $\left(T_{H}+\widetilde{t}\right) u$ and variance $\left(T_{H}+\widetilde{t}\right) \sigma^{2}$ is justified because, as we noted above, empirical evidence from the residential and commercial market confirm that the total ex-post return tends to increase secularly with the holding period (since prices tend to increase, at least in nominal terms), and ex-post risk would be expected to increase over time as one looks further in the future. ${ }^{17}$ Case and Shiller (1987) note that the risk associated with a specific property should be positively related to the length of time elapsed between transactions of that property. One explanation for this is that both buyers and the seller tend to have better information regarding the true market value of a given property if the time after the last transaction of that property is relatively short. On the other hand, after a relatively long holding period, both buyers and the seller tend to have weaker information regarding the true market value of the property, and thus are more likely to agree on a price that

\footnotetext{
17 Again, it would be possible to generalize this specification, but over a wide range of possibilities, our fundamental results would not be affected. We adopt these assumptions primarily for tractability purposes.
} 
differs significantly from the "true" market value. Therefore, the ex-post risk should increase as time passes between transactions.

Four conclusions can be drawn from Theorem 1. First, based on our alternative ex ante perspective, real estate risk can be decomposed into two elements: price risk and marketing period risk. If we confine real estate risk only to price risk, we always understate real estate risk. This underestimation becomes more serious when the uncertainty of marketing period $\operatorname{Var}(\widetilde{t})$ is relatively large and/or when the expected annualized ex-post return $u$ is high. As a result, using risk estimated from historical prices and the time of transactions, ignoring the presence and uncertainty of marketing period, will underestimate real estate risk, and thus lead to marketing period bias.

Second, we recognize that we implicitly are assuming in our analysis that the seller faces neither a liquidity shock nor borrowing constraints; hence he can always wait for the "best" buyer. Huang (2003), however, considers an investor who holds an illiquid asset having to liquidate his asset immediately by a discount price when a liquidity shock occurs. If this is the case, higher ex-ante risk and lower ex-ante return may lead to an even higher marketing period bias. We will discuss this situation later when we consider liquidation risk.

Third, the ex-ante return is the same as the return estimate from traditional approaches that ignore marketing period risk. However, this result holds only when the ex-post return expectations are realized. If the market faces an unanticipated downturn (or upturn), this assumption may be violated, and we can show that the annualized ex-post return should decrease (increase) over time relative to a priori expectations; hence the exante return will be greater (less) than the return estimated from the traditional approach.

Finally, a longer holding period implies lower marketing period risk, hence lower real estate risk and lower marketing period bias, ceteris paribus. This is because the relative magnitudes of the holding period and marketing period change to such a degree that the order of magnitude affect of marketing period risk in comparison with price risk becomes increasingly small. This result provides a formal justification for the conventional wisdom that real estate is more favorable to long-term investors than to short-term investors.

Exhibit 2 summarizes how the alternative distributions of marketing period considered in Appendix 1 affect real estate risk. For example, when the marketing period follows a constant conditional probability of sale, the higher the conditional probability, the less the marketing period risk, and therefore the less the real estate risk. If the marketing period is distributed as an exponential distribution, then the longer the expected marketing period (notice that $E[\tilde{t}]=\eta$ ), the higher the real estate risk, given other things equal.

Empirical Estimations of Marketing Period Risk. Theorem 1 demonstrates that the current approach of using ex-post variance to measure real estate risk has a bias problem. 
The ex-post variance always underestimates real estate risk. However, Theorem 1 also provides a formula to correct for this bias, i.e.

$$
\left(\sigma^{e x-\text { ante }}\right)^{2}=\sigma^{2}+\frac{\operatorname{Var}(t)}{T_{H}+E[t]} u^{2}
$$

Equation (19) tells us that, in order to correct for marketing period bias, besides ex-post return, ex-post risk and holding period, we need to know the distribution of the marketing period random variable. Bond, Hwang, Lin and Vandell (2005) investigate a number of assumptions about the distribution of times to sale, such as the normal, chisquare, gamma and Weibull distributions, and find that the exponential density function explains the U.K. commercial real estate data employed better than the others.

By assuming the marketing period is distributed as the exponential distribution, we next estimate the degree to which marketing period risk together with investment time horizon affect marketing period bias and real estate risk in both the residential and commercial property markets, using U.S. data. ${ }^{18}$

\section{Case I: The U.S. Residential Property Market}

We first consider the U.S. residential property market. We assume an estimated average annual return of $5.02 \%$ and standard deviation of $1.67 \%$, which are derived from the OFHEO U.S. home price index during the period 1980Q1 to 2004Q4.

Exhibit 3 illustrates by how much the ex-ante variance would exceed the ex-post variance under various scenarios of expected marketing period and holding period. From this table, we can readily see first that if the expected time-on-market is zero and real estate is anticipated to be a liquid asset, then real estate risk is completely composed of price risk and the ex-ante variance is the same as the ex-post variance. Second, the degree of underestimation obtained by using the ex-post variance for real estate risk increases with the expected marketing period and decreases with the holding period. For example, if the expected marketing period is eight months, the ex-ante variance will be about two and a half times higher than the ex-post variance if the holding period is only one year, but only $38 \%$ higher if the holding period extends to 10 years.

Therefore, the traditional practice by OFHEO and other related indices of using the ex-post variance as a proxy for the ex-ante variance can seriously underestimate real estate risk, especially when the expected marketing period is high and the holding period is relatively short.

Case II: the U.S. Commercial Property Market

${ }^{18}$ We assume in the following simulations that the OFHEO and NCREIF indices represent either a diversified portfolio of properties or a single property being evaluated by the individual investor whose performance is identical to the averages represented by the indices. We do not adjust for other biases that have been recognized in the literature, such as sample selection bias, "smoothing" through appraisal bias, etc. 
For our empirical evaluation of the U.S. commercial property market, we choose an average annual return of $8.63 \%$ and a standard deviation of $3.20 \%$, which are based on the National Council of Real Estate Investment Fiduciaries (NCREIF) property index during the period 1980Q1 to 2004Q4.

Exhibit 4 summarizes our findings. Similar conclusions to those from Exhibit 3 are obtained, and of a similar magnitude. First, if the expected time-on-market is zero, the ex-ante variance is the same as the ex-post variance. Second, ex-ante variance increases with the expected marketing period and decreases with the holding period. For example, if the expected marketing period is eight months, the ex-ante variance will be about two times higher than the ex-post variance if the holding period is only one year, but is only $30 \%$ higher if the holding period extends to 10 years.

Conclusion with Respect to Marketing Period Bias. A common view in the academic community has been that risk due to real estate illiquidity is trivial when the investment time horizon is long. But little has been studied on the magnitude of the risk associated with marketing period and its uncertainty. The results above strongly suggest that real estate illiquidity risk can be substantial even when the investment time horizon is relatively long, typical of holding periods observed in the market. Therefore, the uncertainty of the marketing period should certainly be considered in the estimation of "true" return and risk in the real estate market.

\section{Real Estate Illiquidity and Liquidation Bias}

Intuition. In addition to marketing period bias (marketing period risk that compounds the effects of price risk), there exists a second potential source of bias in the estimation of market returns and volatility that is related to real estate illiquidity. This we will term liquidation bias. In the financial market, since investors can sell their assets at observed market prices almost immediately, a historical price at time $t$ represents the market price of this asset at that time, meaning that a seller could trade at that price at that time. However, two differences exist between this situation and that in the real estate market due to the uncertainty of the marketing period in the real estate market:

First, in each time period, only a small portion of properties is sold successfully, while a large portion of the properties being offered for sale are still sitting on the market. The transaction prices at time $t$ may reflect prices of the sold properties at that time; however, they may not be reflective of the (unobserved) prices of similar properties that are still waiting on the market.

Second, sellers offering their properties for sale have often waited on the market for a long period of time before selling. Said another way, current real estate transaction prices tend to reflect the prices of those assets that have been on the market for some time. Unlike the financial market, in which the price at time $t$ is the price of those assets recently put on the market, there is a substantial time lag between the time when real estate is placed on the market and when it is sold. Hence, the price of sold properties at 
time $t$ may not represent the price of other properties recently placed on the market. Another way of thinking of this is that sellers would be unlikely to be willing to trade at observed transaction prices at the time at which they place their assets on the market.

The risk of a substantial time lag between the event of sale and event of placing the property on the market is important to real estate investors. For example, a household may experience a surprise liquidity shock, such as a job loss or a divorce, and facing a borrowing constraint, must sell its illiquid real estate in a short time period; firms may have sudden investment opportunities, but face an imperfect and costly external capital market, and hence have to sell their real estate asset immediately when such an opportunity arrives; fund managers may face an unexpected increase in withdrawals, resulting in a need to liquidate a portion of their real estate asset portfolio. In all these situations, when such a shock occurs, real estate investors are forced to sell real estate assets immediately.

How does this possibility of the necessity of a "quick sale" have an impact on real estate pricing, given that such a significant time lag may be present? In order to answer this question, we need to look again at how transaction prices are formed in the real estate market. As observed formally above when we discussed the real estate transaction process, a real estate transaction price can be observed if and only if a buyer's bid price equals or exceeds the seller's reservation price. Hence, transaction prices reflect the prices when a bid price is above the seller's reservation price; i.e., the prices from a truncated distribution of bid prices. This implies that the expected transaction price is likely to be higher than the expected bid price at each point of time.

The "typical" seller has to face the uncertainty of marketing period to receive a bid reflecting the distribution of transaction prices. However, an investor who experiences a surprise liquidity shock and has to sell his real estate asset within a short period of time must accept a price from the distribution of bid prices rather than the distribution of transaction prices. In other words, a bias may result if his return and risk is directly estimated from observed transaction prices, ignoring the possibility of a need for immediate liquidation. We define this bias to be liquidation bias. Because of the close relationship between the existence and magnitude of liquidation bias and the observed marketing period, we may regard liquidation bias as the value of the potentially constrained time on market.

We emphasize that, while marketing period bias as we have described it above, would be expected to affect all sellers to the extent that the marketing period and actual sales price remain uncertain ex ante, the degree of liquidation bias present is dependent upon each individual seller's circumstance with respect to the degree of likelihood of experiencing a forced sale.

Formal Definition of Liquidation Bias. As we saw above in Section III, a real estate transaction price will be observed if and only if a bidding price $P$ equals or exceeds the reservation price $P^{*}$ : 


$$
P^{T}= \begin{cases}P & \text { if } P \geq P^{*}, \\ \text { unobserved } & \text { if } P<P^{*} .\end{cases}
$$

Where:

$$
P=V_{0}+\varepsilon, \quad \varepsilon \sim N\left(0, \sigma_{\varepsilon}^{2}\right)
$$

Equations (')'and (4') can be combined as,

$$
P^{T}=V_{0}+\left[\varepsilon \mid \varepsilon \geq P^{*}-V_{0}\right]
$$

As we know, the only prices that can be observed in the real estate market are transaction prices, and bid prices below the seller's reservation price cannot be observed. As a result, the market valuation distribution cannot be directly observed in the real estate market. How can we impute the unobservable market valuation distribution from available market information?

To answer this question, we rewrite equation (5') as follows,

$$
P^{T}-V_{0}=\varepsilon \mid \varepsilon \geq P^{*}-V_{0}
$$

Equation (20) can be regarded as defining the liquidation bias between the underlying, unobservable market values and the observed transaction prices.

Since the reservation price $P^{*}$ is closely related to the marketing period (TOM), we can rewrite (20) as:

$$
P^{T}-V_{0}=[\varepsilon \mid \varepsilon \geq f(T O M)]
$$

Holding other factors constant, intuition suggests a higher reservation price not only displays a greater liquidation bias between the observable transaction price and the market valuation, but also results in a longer marketing period. Therefore, we should expect a correlation between the length of the marketing period and the degree of liquidation bias.

Normally, we cannot observe the reservation price; however, information on marketing period is readily available. Equation (21) suggests that we may use the available information on transaction prices and time-on-market to impute an estimate of market return and volatility. We undertake this exercise in the following section for the specific case of a uniform distribution of bid prices. 
Estimation of Liquidation Bias under a Uniform Bid Distribution. Suppose $r_{M}$ and $\sigma_{M}$ are the period return and volatility from the market valuation distribution and $r_{T}$ and $\sigma_{T}$ are the period return and volatility based on observed transaction prices. We formally define liquidation bias as,

$$
\begin{aligned}
& \text { return bias }=r_{T}-r_{M} \\
& \text { volatility bias }=\sigma_{M}-\sigma_{T}
\end{aligned}
$$

As before, we assume that an investor purchases a real estate asset at time 0 at a price $P_{0}$, holds it for $T_{H}$ periods, and then offers it on the market for sale. In each marketing period $t(t=0,1,2, \ldots)$, conditional upon a transaction being observed, the total return from this transaction can be estimated as,

$$
\widetilde{R}_{T_{H}+t}^{T}=\frac{P_{T_{H}+t}^{T}-P_{0}}{P_{0}}
$$

and,

$$
P_{T_{H^{+}}}^{T}= \begin{cases}P_{T_{H}+t}^{\text {bid }}, & \text { if } P_{T_{H^{+} t}}^{\text {bid }} \geq p^{*}\left(T_{H}+t\right)+P_{0} \\ \text { unobserved, } & \text { if } P_{T_{H}+t}^{\text {bid }}<p^{*}\left(T_{H}+t\right)+P_{0}\end{cases}
$$

Hence, $P_{T_{H}+t}^{T}$ is uniformly distributed over $\left[\left(T_{H}+t\right) p^{*}+P_{0},\left(T_{H}+t\right) \bar{p}+P_{0}\right]$. As a result, the average period return from this transaction is,

$$
\widetilde{r}_{T_{H}+t}^{T}=\frac{\widetilde{P}^{T}}{P_{0}}
$$

Here, $\widetilde{P}^{T}$ is uniformly distributed over $\left[p^{*}, \bar{p}\right]$.

Similarly, we can obtain the average period return from the underlying market valuation as follows,

$$
\widetilde{r}_{T_{H}+t}^{M}=\frac{\widetilde{P}^{M}}{P_{0}}
$$

Where: $\widetilde{P}^{M}$ is uniformly distributed over $[\underline{p}, \bar{p}]$. Unfortunately, we can only observe market values when $\widetilde{P}^{M} \geq p^{*}$ and cannot observe them when $\widetilde{P}^{M} \in\left[\underline{p}, p^{*}\right)$. In other words, we cannot estimate market return and risk solely based on the transaction prices. However, the relationship between the market valuation and transaction prices can be 
established by the use of marketing period information. We summarize this result in the following theorem.

Theorem 2: Market Valuation, Transaction Prices, and Marketing Periods. Under the assumption above that transaction prices $\widetilde{P}^{T}$ are uniformly distributed over $\left[p^{*}, \bar{p}\right]$ and the underlying market valuation $\widetilde{P}^{M}$ is uniformly distributed over $[\underline{p}, \bar{p}]$, the liquidation bias for a random marketing period $t$ can be represented as

$$
\begin{array}{ll}
\text { 1. } & r_{T}-r_{M}=\sqrt{3} E\left[\widetilde{T}_{M}\right] \sigma_{T} \\
\text { 2. } & \sigma_{M}-\sigma_{T}=E\left[\widetilde{T}_{M}\right] \sigma_{T}
\end{array}
$$

where: $E\left[\widetilde{T}_{M}\right]$ is the expected marketing period.

\section{[Proof provided in Appendix 3]}

Equations (28) and (29) represent the liquidation return and risk bias, respectively. Theorem 2 also illustrates the relationship between liquidation bias and the expected marketing period. Through this relationship, we can use the available observed transaction return $\left(r_{T}\right)$, observed transaction volatility $\left(\sigma_{T}\right)$ and the expected marketing period $\left(E\left[\widetilde{T}_{M}\right]\right)$ to impute the underlying market return $\left(r_{M}\right)$ and volatility $\left(\sigma_{M}\right)$ as follows,

$$
\begin{aligned}
& r_{M}=r_{T}-\sqrt{3} E\left[\widetilde{T}_{M}\right] \sigma_{T} \\
& \sigma_{M}=\left(1+E\left[\widetilde{T}_{M}\right]\right) \sigma_{T}
\end{aligned}
$$

Several conclusions can be drawn from Theorem 2. First, note that as expected, liquidation bias disappears when assets are able to be traded at observable transaction prices with immediate execution (i.e., when $E\left[\widetilde{T}_{M}\right]=0$ ). In other words, there is no liquidation bias in the financial market when observed transaction prices represent market valuation.

Second, unlike in the case of marketing period bias, the holding period $T_{H}$ plays no role in liquidation bias in the real estate market. However, the expected marketing period $\left(E\left[\widetilde{T}_{M}\right]\right)$ plays an important role in the determination of liquidation bias. In particular, liquidation bias increases when the expected marketing period increases, which is consistent with the common perception that a longer expected marketing period implies a higher reservation price, ceteris paribus, hence a greater deviation of transaction prices from the underlying market valuation. 
Third, the "true" market return is always lower than the return estimated from observed transaction prices, and the "true" market volatility is always higher than that estimated from observed transaction prices. Hence, evaluating real estate performance based solely on the transaction sample is likely to result in an overstated risk-adjusted return to those investors who face the potential necessity of a quick sale.

Fourth, liquidation bias increases with the dispersion of observed transaction returns, $\sigma_{T}$. When $\sigma_{T}=0$, liquidation bias disappears. The intuition behind this is straightforward. $\sigma_{T}=0$ implies that all possible bid prices collapse to a single price at each point in time. Put differently, the distribution of possible bidding prices, which becomes a single price, is the same as that of transaction prices, so no bias results.

A final implication of Theorem 2 is that we cannot conclude that real estate submarket $A$ is "better" than real estate submarket $B$ simply by looking at their comparative return and risk estimated from transaction prices. Marketing period information must be also considered. For example, suppose the return and volatility based on the transaction sample are the same in both submarket $A$ and submarket $B$ (i.e., $r_{T}^{A}=r_{T}^{B}$ and $\sigma_{T}^{A}=\sigma_{T}^{B}$ ), but assume the expected marketing period in submarket $\mathrm{A}$ is much higher than that in submarket $\mathrm{B}$ (i.e., $E\left[\widetilde{T}_{M}^{A}\right]>>E\left[\widetilde{T}_{M}^{B}\right]$ ). By Theorem 2, we readily see that $\sigma_{M}^{A}>>\sigma_{M}^{B}$ and $r_{M}^{A}<<r_{M}^{B}$. Therefore, the real estate market in submarket $B$ is actually "better" than that in submarket $A$ in the sense of dominating in both return and risk. Naively looking at the return and volatility based on the transaction prices alone, however, would lead us to conclude that they were identical.

In the financial markets for thickly-traded securities, the marketing period is trivial, and consequently, the market return and volatility are the same as the return and volatility estimated from transaction prices. In the real estate market, however, the marketing period is substantial, and the market return and volatility can be very different from the return and volatility based on the transaction prices. This provides an additional rationale for the notion that returns risk-adjusted returns for real estate obtained through observed transactions data require substantial adjustment to place them in a common framework for analysis with liquid securities, especially for those real estate assets in which the investors potentially face the necessity of quick sale.

Seller Heterogeneity. Thus far, we have assumed all sellers are identical in terms of their reservation price levels over time. However, holding everything else constant, sellers with different financial situations may have very different selling strategies. Sellers who are recently divorced, or face a job loss likely have to sell their houses more quickly than others. Examples of seller motivations that have been studied in the literature include: properties owned by relocated sellers (Turnbull, Sirmans and Benjamin, 1990); vacant properties (e.g. Zuelke, 1987); foreclosure properties (e.g. Forgey, Rutherford and Vanbuskirk, 1994); and time-constraints on sale (e.g. Glower, Hendershott, and Haurin 1998). 
We next discuss how sellers' motivations affect their expected return and volatility. Let us ignore marketing period risk and focus only upon liquidation risk under seller heterogeneity. ${ }^{19}$ Consider two types of sellers: type $A$ has a liquidity constraint with a shorter expected marketing period, denoted by $t$, and type $B$ does not have any financial distress with a longer expected marketing period, denoted by $T(T>t)$. Suppose that the expected period return and volatility that types $A$ and $B$ receive are denoted by $\left(r_{A}, \sigma_{A}\right)$ and $\left(r_{B}, \sigma_{B}\right)$, respectively. We summarize our findings in the following Theorem.

Theorem 3: Risk premium and marketing period. If two sellers of type A and B differ in their expected marketing periods (hence reservation prices) $t$ and $T$, with $t<T$, seller $A$ will suffer a lower period return and a higher volatility in return than borrower $B$, as demonstrated by the relationships

$$
\begin{aligned}
& \text { 1. } r_{B}-r_{A}=\sqrt{3}\left(\frac{T}{1+T}-\frac{t}{1+t}\right) \sigma_{M}>0 \\
& \text { 2. } \sigma_{A}-\sigma_{B}=\frac{T-t}{(1+T)(1+t)} \sigma_{M}>0
\end{aligned}
$$

where: $\sigma_{M}$ is the volatility from market valuation.

\section{[Proof provided in Appendix 4]}

Two points are worth noting from this result. First, type $B$ sellers are expected to experience a longer time on the market and thus have a higher liquidation risk. However, they are also expected to receive a higher expected return and a lower volatility in compensation. The intuition behind this result is quite clear. Type $A$ sellers who are motivated to sell quickly have a lower reservation price and accept earlier, hence receive lower offers. Those sellers who are not motivated to sell quickly will have a higher reservation price and will only accept offers that are relatively high, even if this means an extended wait. This result is also consistent with recent findings by Huang (2003). Huang studies an equilibrium in which agents face surprise liquidity shocks and invest in liquid and illiquid assets. He finds that the illiquid asset generates a higher expected return to compensate its holders for the liquidation risk.

A second implication of Theorem 3 is that type $A$ sellers with financial distress have to sell more quickly than type $B$ sellers. However, they have to give up a higher expected return and a lower volatility. In other words, frequency and immediacy of transaction is closely related to the return and volatility of the transaction properties. The systematic differences in return and volatility among different sellers in the real estate market suggest that properties with owners subject to different selling motivations, hence different marketing periods before sale, should exhibit different patterns of price behavior. These different submarkets, distinguished by brevity of marketing period,

${ }^{19}$ Hence, risk and return essentially represent ex post and not ex ante measures. 
should be analyzed separately, or at least the analytical methodology describing their price behavior should take into account the systematic differences in the frequency and immediacy of transactions (see "Heterogeneous Sellers" in Appendix 5).

Empirical Applications. In this section, we discuss how we can empirically correct for liquidation bias. The required information in our correction method includes transaction prices and the marketing period for each transaction property, both of which are readily available from the market. For simplicity, we assume that sellers in the real estate market are homogeneous. ${ }^{20}$ Hence, there is only one uniform reservation price in the market, and every seller accepts an offer only when the offer price is at least as high as this price. Furthermore, we assume that sellers are 100 percent likely to experience the necessity of forced sale at a specific point in time during the marketing period. ${ }^{21}$

Suppose the estimated return and volatility from the transaction prices are $\hat{r}_{T}$ and $\sigma_{T}$, respectively, and the observed average marketing period is $\hat{T}_{M}$. From equations (30) and (31), we can back into an estimate of the unobservable market return and volatility as follows,

$$
\begin{aligned}
& \hat{r}_{M}=\hat{r}_{T}-\sqrt{3} \hat{T}_{M} \hat{\sigma}_{T} \\
& \hat{\sigma}_{M}=\left(1+\hat{T}_{M}\right) \hat{\sigma}_{T}
\end{aligned}
$$

Equations (30') and (31') prove that, given the same return and volatility estimated from transaction prices, the underlying market return and volatility can be quite divergent. We next look empirically at how the average marketing period affects valuation bias in both the residential and commercial property markets. Again, we assume 100 percent likelihood of forced sale at a specific point in time during the marketing period.

\section{Case I: The US Residential Property Market.}

As before, we assume an observed average annual transaction-based return of $5.02 \%$ and a standard deviation of $1.67 \%$, as taken from OFHEO's U.S. House Price Index during the period 1980Q1 to 2004Q4. Exhibit 5 illustrates how the market return and volatility corrected for liquidation bias change with the average marketing period. As discussed earlier, we have ignored marketing period bias to focus soley on liquidation bias; market return and volatility are essentially the return and volatility absent real estate illiquidity, i.e., with a marketing period $\tilde{t}=0$.

From Exhibit 5, we can see that a higher average marketing period implies a lower effective market return and higher effective market volatility, hence a higher

\footnotetext{
${ }^{20}$ The case of heterogeneous sellers with different reservation prices is discussed in Appendix 4.

${ }^{21}$ This assumption will be relaxed in future work.
} 
liquidation bias, given the same transaction return (5.02\%) and volatility (1.67\%). When the actual marketing period is six months, the effective market return is almost 29 percent lower than the transaction return, and the effective market volatility is over 50 percent higher than the transaction volatility. Therefore, in the presence of a high average marketing period, there is a significant bias problem for the return and volatility estimated from a transaction sample. As we know, in the residential market, the average marketing period is about eight to ten months when the market is "cold", and about four to five months when the market is "hot".22

\section{Case II: The U.S. Commercial Property Market.}

The annual return and volatility of the National Council of Real Estate Investment Fiduciaries (NCREIF) property index during the 1980Q1-2004Q4 period was 8.6\% and $3.2 \%$, respectively. Therefore, as in the residential case, we choose an observed average annual return of $8.6 \%$ and standard deviation of $3.2 \%$ as the transaction-based return and volatility in the commercial market over this period.

Exhibit 6 illustrates the relationship between average marketing period and valuation bias in the commercial market. As in Exhibit 5, we can see that a higher average marketing period implies a lower market return and higher market volatility, given the same transaction return $(8.6 \%)$ and volatility $(3.2 \%)$. When the actual marketing period is eight months, the effective market return is over 43 percent lower than the transaction return, and the effective market volatility is 67 percent higher than the transaction volatility. Given the fact that average marketing periods in commercial markets are often longer than those in residential markets, valuation bias in the commercial market could be an even more serious problem than in the residential market when using the return and volatility estimated from transaction prices.

\section{Conclusions}

This paper documents the potential pricing biases present in traditional real estate valuation methodologies that implicitly assume real estate assets can be sold immediately without waiting. The assumption of immediate execution may be reasonable in the financial market where the time to trade an asset is trivial; however, it is certainly not valid in the real estate market where marketing period is not only uncertain but also substantial. This large magnitude and uncertainty of marketing period exposes an investor additional risk; however, little work has been done to study formally the nature and magnitude of this risk.

\footnotetext{
${ }^{22}$ Over the past three years (up until only recently), the residential real estate market in U.S. could be characterized as a 'hot' market, in which appreciation was high and marketing periods were short (4.5 months). In the early 1990s, however, the market was depressed, and the average marketing period was about 9 months. Krainer (2001) has a good discussion on "hot" and "cold" real estate markets.
} 
We formally define and measure marketing period risk by proposing a new measure of ex-ante return and variance, which replaces the traditional ex-post transactionbased return and variance measure, to capture both price risk and one component of liquidity risk faced by real estate investors. Our findings suggest that the risk associated with ex ante returns is substantially higher than that estimated under traditional methodologies. For example, in the case of U.S. residential market, for an expected marketing period of 8 months, the actual risk to short-term investors (one year holding period) can be as high as 3.4 times that found under traditional estimates. To long-term investors (10 years holding period), although the risk of marketing period can be amortized over the longer holding period, the actual risk can still be almost forty percent higher than that estimated using traditional procedures. A similar result is found for the commercial market: Under an expected marketing period of 8 months, short-term investors incur an effective risk almost 300 percent that assumed under traditional procedures; long-term investors incur an effective risk 30 percent higher. Therefore, traditional real estate valuation methodologies, which assume real estate can be sold immediately and ignore the uncertainty of marketing period, can seriously underestimate real estate risk.

A by-product of this finding is that investors with longer investment time horizons will be less affected by real estate illiquidity due to marketing period risk, not because they do not trade frequently but because the additional risk caused by the uncertainty of marketing period is amortized over the longer holding period. This result is consistent with the common perception that real estate is more favorable to long-term investors.

After correcting for marketing period risk, another bias - which we term liquidation bias, is also found to exist in traditional real estate valuation methodologies, especially for certain classes of investors who face a high probability of immediate "forced" sale. This is because transaction prices are the prices from a "truncated" distribution of the underlying distribution of market valuation by potential buyers. Holding other things equal, a higher reservation price implies a longer expected marketing period and a larger deviation of transaction prices from the "true" market valuation. We provide evidence to support the notion that there is a positive relationship between the expected marketing period and this liquidation bias.

We formally examine how the expected marketing period of real estate affects the magnitude of liquidation bias by considering a model in which the buyers' bid prices are based on market valuation and a transaction price occurs if and only if a bid price equals or exceeds the seller's reservation price. We derive a closed-form relationship among market return/risk, transaction return/risk, and the expected marketing period. We find that a longer expected marketing period implies a larger liquidation bias, ceteris paribus. Consistent with investment theory, investors with a higher expected marketing period are expected to receive a higher return and lower risk in compensation. Looked at in another way, our results suggest that ignoring the existence of a finite and sometimes significant marketing period in real estate can cause the "true" underlying market return to be much lower than the observed transaction-based return and the underlying market risk to be much higher than the observed transaction-based risk. 
We conclude that traditional methods of estimation of real estate return and risk, which borrow in a naïve fashion from finance theory by ignoring real estate illiquidity, not only understate real estate risk but also overstate real estate returns. Our findings extend the empirical results of Fisher, Gatzlaff, Geltner, and Haurin (2003) and Goetzmann and Peng (2003) who seek a "constant liquidity index" to correct for the neglect of the importance of time on market and trading volume on "true" returns. We provide a theoretical foundation for estimating the liquidity bias that results from this phenomenon and undertake simulations that obtain preliminary estimates of its magnitude. The present effort can help us to understand the apparent "risk premium puzzle" in real estate and aid in the development of corrective measures to treat real estate appropriately in a mixed-asset portfolio.

We have made certain simplifying assumptions throughout our analysis for the sake of tractability which bear further scrutiny. First, we assume that ex-post expected nominal prices and total returns increase linearly over the holding period. While this has historically been true empirically over the long run, it is likely to be violated in individual circumstances over the short run when the market faces a downturn. Second, we treat the holding period, rate of bid arrivals, and reservation prices and bids as given, whereas a more generalized model would treat them as endogenous. More fundamentally, our model treats both the ex-post expected return and volatility and price levels as exogenously given and hence independent of the probability of sale. In a more general equilibrium framework, the ex-post expected return and volatility should be statedependent (Clarke R. and Silva H. (1998)), as should the probability of sale (Krainer (2001)). Anglin (2003) discusses how both sale price and probability of sale are correlated and vary over market conditions.

Finally, we have considered the single real estate asset in isolation and not as a part of a portfolio in which nonsystematic risk components, potentially including elements associated with liquidity and valuation bias, can be diversified away or minimized over long-term holding periods during which investors have discretion as to the timing of marketing the asset. There also exists the question as to the relative relevance of our treatment in the residential market, in which a single residential asset lacks diversification potential, vs. the commercial market, in which the institutional investor has many assets which are held in a diversified mixed-asset portfolio. In a subsequent working paper with Bond and Hwang (2005) we address a few of these portfolio issues. 


\section{Exhibit 1}

\section{The Transaction Process for Real Estate}

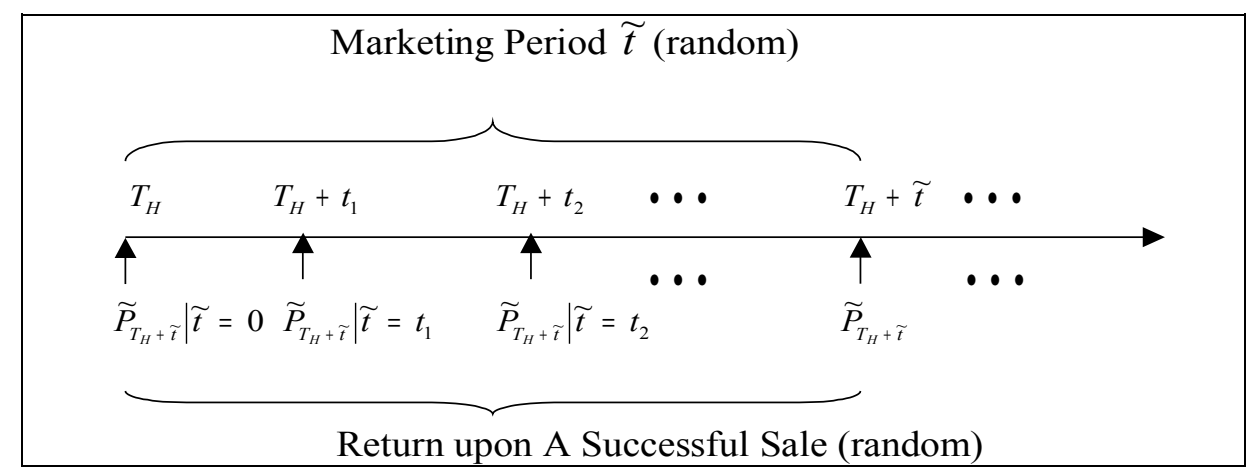

Exhibit 2

The Comparison of the $E X$-ante Variance and the $E x$-post Variance

\begin{tabular}{|c|c|c|c|}
\hline & \multicolumn{3}{|c|}{ Distribution of Marketing Period } \\
\hline & Constant Conditonal Probability of Sale & Uniform Probability of Sale & Exponential Distribution of Sale \\
\hline Probability of Sale & $p_{t}=\lambda(1-\lambda)^{t}, \quad t=0,1,2,3, \ldots$ & $p_{\imath}=\frac{1}{N}, t=0,1,2, \ldots, N-1$ & $p_{r}=\frac{1}{\eta} e^{-\frac{1}{\eta} r}, t \geq 0$ \\
\hline Ex-post variance & $\sigma^{2}$ & $\sigma^{2}$ & $\sigma^{2}$ \\
\hline Ex-ante variance & $\sigma^{2}+\left(\frac{1-\lambda}{\lambda\left[1+\lambda\left(T_{H}-1\right)\right]}\right) u^{2}$ & $\sigma^{2}+\frac{N^{2}-1}{12 T_{H}+6 N-6} u^{2}$ & $\sigma^{2}+\frac{\eta^{2}}{T_{H}+\eta} u^{2}$ \\
\hline $\begin{array}{l}\text { Marketing period } \\
\text { bias }\end{array}$ & $\left(\frac{1-\lambda}{\lambda\left[1+\lambda\left(T_{H}-1\right)\right]}\right) u^{2}$ & $\frac{N^{2}-1}{2 T_{H}+6 N-6} u^{2}$ & $\frac{\eta^{2}}{T_{H}+\eta \eta} u^{2}$ \\
\hline
\end{tabular}


Exhibit 3

\section{Liquidity Bias between Ex-ante and Ex-post Variance Estimates: The U.S. Residential Property Market (Source: OFHEO house price index, 1980Q1 to 2004Q4)}

\begin{tabular}{c|c|c|c|c|c|}
\hline $\begin{array}{c}\text { Expected } \\
\text { Marketing } \\
\begin{array}{c}\text { Period } \\
\text { (months) }\end{array}\end{array}$ & \multicolumn{5}{|c|}{ The Ratio of Ex-ante Variance to Ex-post Variance } \\
\cline { 2 - 6 } & \multicolumn{5}{|c|}{ Holding Period } \\
\hline & 0 & 1 year & 5 years & 10 years & 20 years \\
\hline 0 & 1.00 & 1.00 & 1.00 & 1.00 & 1.00 \\
\hline 2 & 2.51 & 1.22 & 1.05 & 1.02 & 1.01 \\
\hline 4 & 4.01 & 1.75 & 1.19 & 1.10 & 1.05 \\
\hline 6 & 5.52 & 2.51 & 1.41 & 1.22 & 1.11 \\
\hline 8 & 7.02 & 3.41 & 1.71 & 1.38 & 1.19 \\
\hline 10 & 8.53 & 4.42 & 2.08 & 1.58 & 1.30 \\
\hline 12 & 10.04 & 5.52 & 2.51 & 1.82 & 1.43 \\
\hline 14 & 11.54 & 6.68 & 2.99 & 2.10 & 1.58 \\
\hline 16 & 13.05 & 7.88 & 3.54 & 2.42 & 1.75 \\
\hline 18 & 14.55 & 9.13 & 4.13 & 2.77 & 1.95 \\
\hline 20 & 16.06 & 10.41 & 4.76 & 3.15 & 2.16 \\
\hline 24 & 19.07 & 13.05 & 6.16 & 4.01 & 2.64 \\
\hline
\end{tabular}

The table above shows by how much the variance of the returns, after taking the uncertainty of marketing period into account, is greater than that given by traditional estimation methods using the unadjusted sales price as an unbiased estimate of market value. For example, if a homeowner holds a property for 10 years and the expected marketing period is 8 months, the ex ante risk faced by the homeowner is $38 \%$ higher than that given by the traditional ex post estimation. 


\section{Exhibit 4}

\section{Liquidity Bias between Ex-ante and Ex-post Return Estimates: The US Commercial Property Market (Source: NCREIF property performance index, 1980Q1 to 2004Q4)}

\begin{tabular}{|c|c|c|c|c|c|}
\hline \multirow{2}{*}{$\begin{array}{c}\text { Expected } \\
\text { Marketing } \\
\begin{array}{c}\text { Period } \\
\text { (months) }\end{array}\end{array}$} & \multicolumn{5}{|c|}{ The Ratio of Ex-ante Variance to Ex-post Variance } \\
\cline { 2 - 6 } & \multicolumn{5}{|c|}{ Holding Period } \\
\hline & 0 & 1 year & 5 years & 10 years & 20 years \\
\hline 0 & 1.00 & 1.00 & 1.00 & 1.00 & 1.00 \\
\hline 2 & 2.21 & 1.17 & 1.04 & 1.02 & 1.01 \\
\hline 4 & 3.42 & 1.61 & 1.15 & 1.08 & 1.04 \\
\hline 6 & 4.64 & 2.21 & 1.33 & 1.17 & 1.09 \\
\hline 8 & 5.85 & 2.94 & 1.57 & 1.30 & 1.16 \\
\hline 10 & 7.06 & 3.75 & 1.87 & 1.47 & 1.24 \\
\hline 12 & 8.27 & 4.64 & 2.21 & 1.66 & 1.35 \\
\hline 14 & 9.49 & 5.57 & 2.61 & 1.89 & 1.47 \\
\hline 16 & 10.70 & 6.54 & 3.04 & 2.14 & 1.61 \\
\hline 18 & 11.91 & 7.55 & 3.52 & 2.42 & 1.76 \\
\hline 20 & 13.12 & 8.58 & 4.03 & 2.73 & 1.93 \\
\hline 24 & 15.55 & 10.70 & 5.16 & 3.42 & 2.32 \\
\hline
\end{tabular}

The table above shows by how much the variance of the returns, after taking the uncertainty of marketing period into account, is greater than that given by traditional estimation methods using the unadjusted sales price as an unbiased estimate of market value. For example, if an investor holds a property for 10 years and the expected marketing period is 8 months, the ex ante risk faced by the investor is $30 \%$ higher than that given by traditional ex post estimation. 


\section{Exhibit 5}

\section{Liquidation Bias: The US Residential Property Market (Source: OFHEO house price index, 1980Q1 to 2004Q4)}

\begin{tabular}{c|cc|cc}
\hline \multirow{2}{*}{$\hat{T}_{M}$} & \multicolumn{2}{|c|}{ Market Valuation } & \multicolumn{2}{c}{ Liquidation Bias: } \\
\cline { 2 - 5 } (Months) & Market Return & Market Volatility & Return Bins & Volatility Bias \\
\hline 0 & $5.02 \%$ & $1.67 \%$ & $0.00 \%$ & $0.00 \%$ \\
2 & $4.54 \%$ & $1.95 \%$ & $0.48 \%$ & $0.28 \%$ \\
4 & $4.06 \%$ & $2.23 \%$ & $0.96 \%$ & $0.56 \%$ \\
6 & $3.57 \%$ & $2.51 \%$ & $1.45 \%$ & $0.84 \%$ \\
8 & $3.09 \%$ & $2.78 \%$ & $1.93 \%$ & $1.11 \%$ \\
10 & $2.61 \%$ & $3.06 \%$ & $2.41 \%$ & $1.39 \%$ \\
12 & $2.13 \%$ & $3.34 \%$ & $2.89 \%$ & $1.67 \%$ \\
\hline
\end{tabular}

Market return and volatility represent the return and volatility received by sellers who must sell their real estate assets immediately. The table above shows how we can impute the "true" market return and volatility from the return and volatility estimated from a transaction-based sample, given the expected marketing period. For example, suppose the observed transaction return and volatility are 5.02\% and $1.67 \%$, respectively, and assume the average expected marketing period is 8 months. Then the "true" market return and volatility (i.e., assuming instantaneous sale, with liquidation risk but without marketing period risk) are $3.09 \%$ and $2.78 \%$, respectively. The liquidation bias is simply the difference between the market return/volatility and the transaction return/volatility.

\section{Exhibit 6}

\section{Liquidation Bias: The US Commercial Property Market (Source: NCREIF property performance index, 1980Q1 to 2004Q4)}

\begin{tabular}{c|cc|cc}
\hline \multirow{2}{*}{$\hat{T}_{M}$} & \multicolumn{2}{|c|}{ Market Valuation } & \multicolumn{2}{c}{ Liquidation Bias: } \\
\cline { 2 - 5 } (Months) & Market R eturn & Market Volatility & Return Bias & Volatility Bias \\
\hline 0 & $8.63 \%$ & $3.20 \%$ & $0.00 \%$ & $0.00 \%$ \\
2 & $7.71 \%$ & $3.73 \%$ & $0.92 \%$ & $0.53 \%$ \\
4 & $6.78 \%$ & $4.27 \%$ & $1.85 \%$ & $1.07 \%$ \\
6 & $5.86 \%$ & $4.80 \%$ & $2.77 \%$ & $1.60 \%$ \\
8 & $4.93 \%$ & $5.33 \%$ & $3.70 \%$ & $2.13 \%$ \\
10 & $4.01 \%$ & $5.87 \%$ & $4.62 \%$ & $2.67 \%$ \\
12 & $3.09 \%$ & $6.40 \%$ & $5.54 \%$ & $3.20 \%$ \\
\hline
\end{tabular}

Market return and volatility represent the return and volatility received by the sellers who must sell their real estate assets immediately. The table above shows how we can impute the "true" market return and volatility from the return and volatility estimated from a transaction-based sample, given the expected marketing period. For example, suppose the transaction return and volatility are $8.63 \%$ and $3.2 \%$, respectively, and assume the expected marketing period is 10 months. Then the "true" market return and volatility are $4.01 \%$ and $5.87 \%$, respectively. The liquidation bias is simply the difference between the market return/volatility and the transaction return/volatility. 


\section{Appendix 1}

\section{Expected Marketing Period and Its Uncertainty under Alternative Assumptions about the Distribution of the Probability of Sale over Time}

\section{Case 1: Constant Conditional Probability of Sale}

In this case, the conditional probability (or hazard rate) of selling a similar property in each market period is constant. Suppose the hazard rate is $\lambda(\lambda \leq 1)$, then the probability of selling the property in each marketing period $t(t=0,1,2, \ldots)$ is a geometric distribution,

$$
p_{t}=\lambda(1-\lambda)^{t}
$$

Inserting the equation above into equations (11) and (12), we can obtain,

$$
\begin{gathered}
E[\tilde{t}]=\frac{1}{\lambda}-1 \\
\operatorname{Var}(\tilde{t})=\frac{1}{\lambda^{2}}(1-\lambda)
\end{gathered}
$$

Therefore, a lower hazard rate (i.e., a less liquid market) indicates a higher expected marketing period $(E[\tilde{t}] / \partial \lambda<0)$ and higher uncertainty of time of sale ( $\partial \operatorname{Var}(\tilde{t}) / \partial \lambda<0)$. When $\lambda=1$ (i.e., a perfectly liquid asset), both $E[\tilde{t}]$ and $\operatorname{Var}(\tilde{t})$ become zero.

\section{Case 2: Uniform Probability of Sale}

Suppose the probability of sale is constant across all marketing periods. Assume that $N-1$ is the maximum marketing period. Then the probability of sale in each marketing period $t(t=0,1,2, \ldots, N-1)$ is

$$
p_{t}=\frac{1}{N}
$$

We thus have,

$$
\begin{gathered}
E[\tilde{t}]=\frac{N-1}{2} \\
\operatorname{Var}(\tilde{t})=\frac{N^{2}-1}{12}
\end{gathered}
$$

Equations (A1.5) and (A1.6) demonstrate again that a larger $N$ (less liquidity) implies a longer expected marketing period and higher uncertainty of time of sale. In 
particular, the expected marketing period and the volatility (standard deviation) of sale time will both increase at about the same order of magnitude as $N$; when $N$ doubles, the expected marketing period and the uncertainty of sale time almost double.

\section{Case 3: Exponential Distribution of Sale}

Suppose real estate sales follow the Poisson distribution. Then the marketing period follows an exponential density function with parameter $\eta$,

$$
p_{t}=\frac{1}{\eta} e^{-\frac{1}{\eta} t}, \quad t \geq 0
$$

We thus have,

$$
\begin{gathered}
E[\widetilde{t}]=\eta \\
\operatorname{Var}(\widetilde{t})=\eta^{2}
\end{gathered}
$$

Therefore, the parameter $\eta$ represents the expected marketing period. Again we have, for a higher $\eta$ (less liquidity), both the expected marketing time and its volatility are expected to increase at the same order of magnitude. 


\section{Appendix 2}

\section{Proof of Theorem 1}

By the definitions of ex ante expected return and variance (i.e., equations (13) and (14)), and the assumed distribution of ex post return with mean $\left(T_{H}+\widetilde{t}\right) u$ and variance $\left(T_{H}+\widetilde{t}\right) \sigma^{2}$, we have

$$
\begin{gathered}
E^{\text {ex- ante }}\left[\widetilde{R}_{\widetilde{t}+T_{H}}\right]=\sum_{t=0}^{\infty} E\left[\widetilde{R}_{t+T_{H}}\right] p_{t}=u \sum_{t=0}^{\infty}\left(t+T_{H}\right) p_{t} \\
=u\left(T_{H}+E[\widetilde{t}]\right) \\
\operatorname{Var}^{\text {ex- ante }}\left(\widetilde{R}_{\widetilde{t}+T_{H}}\right)=\sum_{t=0}^{\infty} E\left[\widetilde{R}_{\widetilde{t}+T_{H}}-E^{\text {ex- ante }}\left[\widetilde{R}_{\widetilde{t}+T_{H}}\right]\right]^{2} p_{t} \\
=\sum_{t=0}^{\infty} E\left[\widetilde{R}_{t+T_{H}}^{2}\right] p_{t}-E^{e x-\text { ante }}\left[\widetilde{R}_{\widetilde{t}+T_{H}}\right]^{2} \\
=\sum_{t=0}^{\infty}\left(\left[t+T_{H}\right] \sigma^{2}+\left[t+T_{H}\right]^{2} u^{2}\right) p_{t}-E^{\text {ex- ante }}\left[\widetilde{R}_{\widetilde{t}+T_{H}}\right]^{2}
\end{gathered}
$$

Inserting equation (A2.1) into equation (A2.2) yields,

$$
\operatorname{Var}^{e x-\text { ante }}\left(\widetilde{R}_{\tilde{t}+T_{H}}\right)=\left(T_{H}+E[\tilde{t}]\right) \sigma^{2}+\operatorname{Var}(\tilde{t}) u^{2}
$$

Hence, the annualized ex-ante return and variance are,

$$
\begin{aligned}
& u^{\text {ex-ante }}=u \\
& \left(\sigma^{\text {ex-ante }}\right)^{2}=\sigma^{2}+\frac{\operatorname{Var}(\tilde{t})}{T_{H}+E[\widetilde{t}]} u^{2}
\end{aligned}
$$

Q.E.D. 


\section{Appendix 3}

\section{Proof of Theorem 2}

Based on equations (26) and (27), the transaction return (annualized) and the market return (annualized) can be expressed as:

$$
\widetilde{r}_{T_{H}+t}^{T}=\frac{\widetilde{P}^{T}}{P_{0}}
$$

where, $\widetilde{P}^{T}$ is uniformly distributed over $\left[p^{*}, \bar{p}\right]$

$$
\widetilde{r}_{T_{H}+t}^{M}=\frac{\widetilde{P}^{M}}{P_{0}}
$$

where, $\widetilde{P}^{M}$ is uniformly distributed over $[\underline{p}, \bar{p}]$.

Hence, we have,

$$
\begin{aligned}
& r_{M}=E\left[\frac{\widetilde{P}}{P_{0}}\right]=\frac{(\bar{p}+\underline{p})}{2 P_{0}} \\
& r_{T}=E\left[\frac{\widetilde{P}^{T}}{P_{0}} \mid \widetilde{P}^{T} \geq p^{*}\right]=\frac{p^{*}+\bar{p}}{2 P_{0}} \\
& \sigma_{M}^{2}=\operatorname{Var}\left[\frac{\widetilde{P}}{P_{0}}\right]=\frac{(\bar{p}-\underline{p})^{2}}{12 P_{0}^{2}} \\
& \sigma_{T}^{2}=\operatorname{Var}\left[\frac{\widetilde{P}^{T}}{P_{0}} \mid \widetilde{P} \geq p^{*}\right]=\frac{\left(\bar{p}-p^{*}\right)^{2}}{12 P_{0}^{2}}
\end{aligned}
$$

Equations (8) and (10) yield,

$$
E\left[\widetilde{T}_{M}\right]=\frac{p^{*}-\underline{p}}{\bar{p}-p^{*}}
$$

Given,

$$
\frac{(\bar{p}+\underline{p})}{2 P_{0}}=\frac{\left(\bar{p}+p^{*}\right)}{2 P_{0}}-\sqrt{3}\left(\frac{p^{*}-\underline{p}}{\bar{p}-p^{*}}\right) \sqrt{\frac{\left(\bar{p}-p^{*}\right)^{2}}{12 P_{0}^{2}}}
$$

and equations (A2.4) to (A2.6), we therefore have, 


$$
r_{M}=r_{T}-\sqrt{3} E\left[\widetilde{T}_{M}\right] \sigma_{T}
$$

Similarly, we can rewrite

$$
\sqrt{\frac{(\bar{p}-\underline{p})^{2}}{12 P_{0}^{2}}}=\left[1+\frac{p^{*}-\underline{p}}{\bar{p}-p^{*}}\right] \sqrt{\frac{\left(\bar{p}-p^{*}\right)^{2}}{12 P_{0}^{2}}}
$$

From (A2.10) and equations (A2.5), (A2.6) and (A2.7), we therefore have

$$
\sigma_{M}=\left(1+E\left[\widetilde{T}_{M}\right]\right) \sigma_{T}
$$

Q.E.D. 


\section{Appendix 4}

\section{Proof of Theorem 3}

Given the expected marketing time $t$ for type A sellers and T for type B sellers, and equations (A3.9) and (A3.11), we have,

$$
\begin{aligned}
& r_{A}-r_{M}=\sqrt{3} t \sigma_{A} \\
& \sigma_{M}-\sigma_{A}=t \sigma_{A} \\
& r_{B}-r_{M}=\sqrt{3} T \sigma_{B} \\
& \sigma_{M}-\sigma_{B}=T \sigma_{B}
\end{aligned}
$$

Rewriting equations (A4.2) and (A4.4) yields,

$$
\begin{aligned}
& \sigma_{A}=\frac{1}{1+t} \sigma_{M} \\
& \sigma_{B}=\frac{1}{1+T} \sigma_{M}
\end{aligned}
$$

From equations (A4.5) and (A4.6), we have,

$$
\sigma_{A}-\sigma_{B}=\frac{T-t}{(1+T)(1+t)} \sigma_{M}>0
$$

From equations (A4.1), (A4.3), (A4.5) and (A4.6), we have,

$$
\begin{aligned}
& r_{B}=r_{M}+\frac{\sqrt{3} T}{1+T} \sigma_{M} \\
& r_{A}=r_{M}+\frac{\sqrt{3} t}{1+t} \sigma_{M}
\end{aligned}
$$

Therefore,

$$
r_{B}-r_{A}=\sqrt{3}\left(\frac{T}{1+T}-\frac{t}{1+t}\right) \sigma_{M}>0
$$

Q.E.D. 


\section{Appendix 5}

\section{Heterogeneous Sellers}

We have heretofore assumed all sellers are identical in terms of their reservation price characteristics. However in reality, differentiated sellers coexist in the real estate market. Sellers with different financial situations, as discussed earlier, receive different transaction returns and volatilities. Suppose there are $N$ different types of sellers in the market, the average marketing period for sellers of type $i(i=1,2, \ldots, N)$ is $\hat{T}_{M}^{i}$. Assume the proportional representation of sellers of type $i$ is given by $g_{i}$, and denote the return and volatility for sellers of type $i$ based on the transaction sample as $\hat{r}_{T}^{i}$ and $\hat{\sigma}_{T}^{i}$, respectively. Then, we can estimate the market return and volatility using one of two approaches. The first approach is to apply equations (30) and (431 to each type of seller and estimate market return and volatility separately. The second approach is to take into account the differences in the proportional representation of each seller type and estimate market return and volatility as follows,

$$
\begin{gathered}
\hat{\sigma}_{M}=\frac{\sum_{i=1}^{N} \hat{\sigma}_{T}^{i} g_{i}}{\sum_{i=1}^{N} \frac{1}{1+\hat{T}_{M}^{i}} g_{i}} \\
\hat{u}_{M}=\sum_{i=1}^{N} \hat{r}_{T}^{i} g_{i}-\hat{\sigma}_{M} \sum_{i=1}^{N} \frac{\sqrt{3} \hat{T}_{M}^{i}}{1+\hat{T}_{M}^{i}} g_{i}
\end{gathered}
$$




\section{References}

Anglin P. (2003), "The Value and Liquidity Effects of A Change in Market Conditions," Working Papers, University of Windsor

Arnold M. (1999), "Search, Bargaining and Optimal Asking Prices," Real Estate Economics, 27:453-482

Bailey M., Muth R. and Nourse H. (1963), “A Regression Method for Real Estate Price Index Construction,” Journal of the American Statistical Association, 58, 933-42

Bond S., Hwang S., Lin, Z., and Vandell, K.D., (2005), "Does Marketing Period RiskMatter in the UK Commercial Real Estate Market? Working paper, University of Cambridge (under revision).

Case B. and Shiller R. (1987), "Prices of Single-Family Homes Since 1970: New Indexes For Four Cities," New England Economic Review, 45-56.

Clarke R. and Silva H. (1998), "State-Dependent Asset Allocation”, Journal of Portfolio Management, 57-64

Clayton J., Geltner D. and Hamilton S. (2001), "Smoothing in Commercial Property Valuations: Evidence from Individual Appraisals," Real Estate Economics, 337-360

DeGroot M. (1970), Optimal Statistical Decisions. New York: McGraw-Hill.

Dombrow J., Knight J. and Sirmans C. (1997), "Aggregation Bias in Repeat-Sales Indices", Journal of Real Estate Finance and Economics, 75-88

Englund P., Quigley J. and Redfearn C. (1999), “Do Housing Transactions Provide Misleading Evidence About The Course of Housing Values?” Working Paper.

Firstenberg, Ross and Zisler (1988), "Real Estate: The Whole Story", Journal of Portfolio Management; 14(3), 22-34.

Fisher J., Gatzlaff D., Geltner D., and Haurin D. (2003), "Controlling for the Impact of Variable Liquidity in Commercial Real Estate Price Indices," Real Estate Economics, 31, 269-303.

Forgey F., Rutherford R. and Springer T. (1996), "Search and Liquidity in Single-Family Housing," Real Estate Economics 24, 273-392

Gatzlaff D. and Haurin D. (1997), "Sample Selection Bias and Repeat-Sales Index Estimates," Journal of Restate Finance and Economics, 33-50 
Gatzlaff D. and Haurin D. (1998), "Sample Selection and Biases in Local House Value Indices," Journal of Urban Economics, 199-222

Geltner D. (1989), "Estimating Real Estate's Systematic Risk from Aggregate Level Appraisal-Based Returns", AREUEA Journal, 463-481

Geltner D. (1991), "Smoothing in Appraisal-Based Returns," Journal of Real Estate Finance and Economics, p327-345

Geltner D. (1993), “Temporary Aggregation in Real Estate Return Indices”, AREUEA Journal, 141-166

Geltner D. and Goetzmann W. (2000), “Two Decades of Commercial Property Returns: A Repeated-Measures Regression -Based Version of the NCREIF Index", Journal of Real Estate Finance and Economics, 5-21.

Geltner D., MacGregor B. and Schwann G. (2003), "Appraisal Smoothing and Price Discovery in Real Estate Markets," Urban Studies, 1047-1064

Giliberto M. (1988), “A Note on the Use of Appraisal Data in Indexes of Performance Measure", AREUEA Journal, 77-83

Glower M., Haurin D. and Hendershott P. (1998), "Selling Price and Selling Time: The Impact of Seller Motivation," Real Estate Economics, 719-740

Goetzmann W. and Peng L. (2002), "The Bias of the RSR Estimator and the Accuracy of Some Alternatives", Real Estate Economics, 13-39

Goetzmann W. and Peng L. (2003), "Estimating Indices in the Presence of Seller Reservation Prices," Working Paper, Yale University

Goodman J. (1998), “Aggregation of Local Housing Markets”, Journal of Real Estate Finance and Economics, 45-53

Haurin D (1988), "The Duration of Marketing Time of Residential Housing," AREUEA Journal 16, 396-410

Heckman J. (1979), "Sample Selection Bias as A Specification Error,” Econometrica, 153-797

Hoag J. (1980), “Toward Indices of Real Estate Value and Return”, Journal of Finance, May.

Huang M. (2003), "Liquidity Shocks and Equilibrium Liquidity Premia," Journal of Economic Theory, 105-129 
Ibbotson R. and Fall C. (1979), "The United States Market Wealth Portfolio", Journal of Portfolio Management, Fall.

Ibbotson R. and Sinquefield R. (1982), "Stocks, Bonds, Bills and Inflation: The Past and the Future", The Financial Analysts Research Foundation

Ibbotson Associates, Michael W. Barad (Editor) (2005), Stocks, Bonds, Bills, and Inflation (Sbbi) Yearbook (Valuation Edition).

Kallberg J., Liu C. and Greig W. (1996), "The Role of Real Estate in the Portfolio Allocation Process," Real Estate Economics, 359-377

Kelleher R. (1976), “ How Real Estate Stacks Up to the S\&P 500”, Real Estate Review, Summer.

Krainer J. (2001), “A Theory of Liquidity in Residential Real Estate Markets," Journal of Urban Economics, 32-53

Lin, Z. Liquidity and Pricing Biases in the Real Estate Market. Unpublished Ph.D. Dissertation, University of Wisconsin-Madison, Real Estate and Urban Land Economics, 2004.

Lippman S. and McCall J (1976), “The Economics of Job Search: A Survey," Economic Inquiry 14, 155-89.

Lippman S. and McCall J. (1986), “An Operational Measure of Liquidity," American Economic Review 76, 43-55

Miceli T. (1989), "The Optimal Duration of Real Estate Listing Contracts," Journal of the American Real Estate and Urban Economics Association 17, 267-277

Munneke H. and Slade B. (2000), "An Empirical Study of Sample-Selection Bias in Indices of Commercial Real Estate," Journal of Real Estate Finance and Economics, 4564.

Quan D. and Quigley J. (1991), "Price Formation and the Appraisal Function in Real Estate Markets," Journal of Real Estate Finance and Economics 4, 127-146

Quigley J. (1995), "A Simple Hybrid Model for Estimating Real Estate Price Indexes," Journal of Housing Economics, 1-12

Read C. (1988), "Price Strategies for Idiosyncratic Goods - the Case of Housing," Journal of the American Real Estate and Urban Economics Association 16, 379-395

Ross S. and Zisler R. (1991), "Risk and Return in Real Estate", Journal of Real Estate Finance and Economics, 175-190 
Salant S (1991), "For Sale by Owner: When to Use a Broker and How to Price the House," Journal of Real Estate Finance and Economics 4, 157-173.

Shiller R. (1991), “Arithmetic Repeat Sales Price Estimators”, Journal of Housing Economics, 110-126

Sirmans C., Turnbull G. and Dombrow J. (1995), "Quick House Sales: Seller Mistake or Luck?" Journal of Housing Economics, 230-243.

Thomas R. and Stekler H. (1983), “A Regional Forecasting Model for Construction Activity", Regional Science and Urban Economics, 557-577

Trippi R. (1977), "Estimating the Relationship between Price and Time of Sale in Investment Property," Management Science, 23, 838-842.

Turnbull G., Sirmans C. and Benjamin J. (1990), "Do Corporations Sell Houses for Less? A Test of Housing Market Efficiency," Applied Economics, 1389-98

Yavas A. (1992), "A Simple Search and Bargaining Model of Real Estate Markets," Journal of the American Real Estate and Urban Economics Association 20, 533-548.

Zerbst R. and Cambon B. (1984), "Historical Returns on Real Estate Investments", Journal of Portfolio Management, Spring.

Zuehlke T. (1987), "Duration Dependence in the Housing Market," Review of Economics and Statistics 69, 701-704 